\title{
Effects of natalizumab therapy on intrathecal antiviral antibody responses in MS
}

\author{
Fabienne Largey, PhD, Ivan Jelcic, PhD, Mireia Sospedra, PhD, Christoph Heesen, MD, Roland Martin, MD, and \\ Ilijas Jelcic, MD
}

Neurol Neuroimmunol Neuroinflamm 2019;6:e621. doi:10.1212/NXI.0000000000000621

\section{Abstract}

\section{Objective}

To investigate the effects of natalizumab (NAT) treatment on intrathecally produced antiviral antibodies in MS.

\section{Methods}

We performed a longitudinal, observational study analyzing both serum and CSF samples collected before and during NAT treatment for antibodies against measles, rubella, mumps, influenza, entero, herpes, and polyoma viruses, including JC polyomavirus (JCV) and its nearest homologue BK polyomavirus (BKV), and bacterial control antigens by ELISA to determine the antigen-specific CSF antibody index (CAI). CAI $\geq 1.5$ indicated intrathecal synthesis of antigen-specific antibodies. Oligoclonal bands (OCBs) by isoelectric focusing and total IgG, IgM, and IgA by immunonephelometry were analyzed additionally.

\section{Results}

Intrathecal synthesis of JCV- and BKV-specific IgG was detected in $20 \%$ of patients with MS at baseline and was lost significantly more frequently during NAT treatment compared with other intrathecal antiviral and antibacterial antibody reactivities. Peripheral JCV- and BKV-specific antibody responses persisted, and no cross-reactivity between JCV- and BKV-specific CSF antibodies was found. Intrathecal production of antibodies against measles, rubella, and zoster antigens (MRZ reaction) was most prevalent and persisted ( $73.3 \%$ before vs $66.7 \%$ after 1 year of NAT therapy). CSF OCBs also persisted (93.3\% vs $80.0 \%$ ), but total CSF IgG and IgM levels declined significantly.

\section{Conclusions}

These data indicate that JCV-specific antibodies are produced intrathecally in a minority of patients with MS, and NAT treatment affects the intrathecal humoral immune response against JCV relatively specifically compared with other neurotropic viruses. Further studies are needed to determine whether this effect translates to higher risk of progressive multifocal leukoencephalopathy development.
Correspondence

Dr. llijas Jelcic

Ilijas.Jelcic@usz.ch

From the Neuroimmunology and Multiple Sclerosis Research Section (F.L., Ivan Jelcic, M.S., R.M., Ilijas Jelcic), Department of Neurology, University Hospital of Zurich, Switzerland; and Institute for Neuroimmunology and Multiple Sclerosis (inims) (C.H.), Center for Molecular Neurobiology (ZMNH), University Medical Center Hamburg-Eppendorf, Hamburg, Germany. 


\section{Glossary}

$\mathbf{A U}=$ arbitrary unit $\mathbf{B B B}=$ blood-brain barrier; $\mathbf{C A I}=\mathrm{CSF}$ antibody index; $\mathbf{C M V}=$ cytomegalovirus; $\mathbf{C O V}=$ cutoff value; EBV = Epstein-Barr virus; EBNA-1 = EBV nuclear antigen-1; EBV-VCA = EBV viral capsid antigen; HSV = herpes simplex virus; JCV = JC polyomavirus; MRZ reaction = measles, rubella, and zoster antigens; $\mathbf{N A T}=$ natalizumab; $\mathbf{O C B}=$ oligoclonal band; $\mathbf{O D}=$ optical density; PML = progressive multifocal leukoencephalopathy; RRMS = relapsing-remitting MS; VZV = varicella zoster virus.

Natalizumab (NAT) is a highly efficacious treatment for relapsing-remitting MS (RRMS) and hinders immune cells from entry into the CNS. However, this also compromises physiologic CNS immune surveillance and is an important reason for NAT-associated progressive multifocal leukoencephalopathy (NAT-PML). PML is an opportunistic CNS infection with JC polyomavirus (JCV) and has emerged as a serious adverse event in 778 NAT-treated patients worldwide (incidence of 4.2/1,000) with fatal outcome in $23 \%$ of cases, ${ }^{1,2}$ whereas other CNS infections occur far less frequently (incidence of herpes virus CNS infections at 0.2 / $1,000){ }^{3}$ Why NAT-treated patients are more prone to develop PML than other viral CNS infections is not clear. ${ }^{4}$

NAT impairs entry of B and plasma cells into the CNS and is associated with decreased total CSF IgG and IgM levels. ${ }^{5-7}$ Moreover, NAT may reduce the prevalence, number, and/or intensity of CSF oligoclonal bands (OCBs), ${ }^{7-9}$ whereas the influence on polyspecific intrathecal antibody reactivity to measles, rubella, and zoster (MRZ reaction) remains less examined. ${ }^{7}$ Positive OCBs and MRZ reaction in CSF are common, well established, and stable surrogates of ongoing intrathecal humoral immune reaction in MS. ${ }^{10,11}$ Intrathecal production of JCV-specific antibodies has been described in $3.6 \%$ of patients with $\mathrm{MS}^{12}$ and thus may be part of the "polyspecific" CSF humoral immune reaction, which is usually depicted by the MRZ reaction, but which extends to many other viruses. ${ }^{12-15}$ Of interest, JCV-specific CSF antibody production was not found in NAT-treated patients with MS, but in 55\% of patients with NAT-PML, ${ }^{16}$ indicating that it is an important aspect of protective immune responses against PML.

Here, we addressed how NAT influences the spectrum of intrathecally produced antibodies against various pathogens including JCV.

\section{Methods}

\section{Patients and samples}

Paired serum and CSF samples were collected from 15 patients (male/female ratio 1:4; mean age 40.13 years [range 18-53 years]) diagnosed with RRMS according to 2005 revised McDonald criteria ${ }^{17}$ at the University Medical Center Hamburg-Eppendorf, Hamburg, Germany, before NAT (V0), and after 12 months (V12) and 24 months (V24, only from 6 patients, loss of follow-up in 9 patients due to denial of further participation) of NAT treatment (300 mg IV every 4 weeks). The patients had not received steroids 4 weeks before
NAT treatment or any immunomodulatory or immunosuppressive agent 3 months before NAT treatment. Additional 25 serum samples from healthy donors were used for determining the cutoff value (COV) of seropositivity in JCV ELISA.

\section{Standard protocol approvals, registrations, and patient consents}

The local ethics committee (Ethik-Kommission der Ärztekammer Hamburg, Germany, protocol No. 2758) approved the study. All patients gave written informed consent.

\section{Antibody detection in serum and CSF}

Antibody reactivity against the following viral lysates and bacterial antigens was tested using commercial ELISA kits from Euroimmun (Lübeck, Germany): measles, rubella, mumps, herpes simplex virus type $1 / 2$ (HSV-1/HSV-2), cytomegalovirus (CMV), varicella zoster virus (VZV), influenza virus $A$ and $B$ (influenza $A$ and $B$ ), and enterovirus lysates; Epstein-Barr virus (EBV) nuclear antigen-1 (EBNA-1) and EBV viral capsid antigen (EBV-VCA); and tetanus toxoid (tetanus), diphtheria toxoid (diphtheria), Helicobacter pylori, and Chlamydophila pneumoniae antigens. Antipolyomaviral IgG reactivity was determined using BK polyomavirus (BKV)-, KI polyomavirus (KIV)-, or WU polyomavirus (WUV)-viral protein 1 (VP1) fused to glutathione S-transferase (kind gift from Robert L. Garcea, Boulder, CO) or JCV-VP1 (MAD1 strain, Life Science Incubator, Bonn, Germany), as described previously. ${ }^{18,19}$ Briefly, ELISA plates were coated with $200 \mathrm{ng}$ of the respective polyomavirus-VP1/well and incubated with serum (1:400, 1:2,020 dilutions) and CSF (1:2, 1:10, 1:100, and 1:1,000 dilutions). Human IgG was detected using biotinconjugated anti-human mouse $\mathrm{Fc}$ antibody and avidin horseradish peroxidase (eBioscience, Frankfurt, Germany). Optical density at $450 \mathrm{~nm}\left(\mathrm{OD}_{450}\right)$ was assessed using a Synergy $\mathrm{H} 1$ reader (BioTek, Luzern, Switzerland). Antibody reactivity was assessed in arbitrary units (AUs) using a standard curve obtained from a serial dilution of the respective standard serum for interpolating ODs by 4 parameter logistic curve fit. AUs within the linear part of the standard curve were multiplied by the corresponding dilution factor to obtain absolute AU. Highly reactive samples exceeding the linear limits of the standard curve were further diluted.

The antigen-specific $\mathrm{CSF} /$ serum antibody index $\left(\mathrm{CAI}_{\text {spec }}\right)$ was calculated according to Reiber. ${ }^{20}$ Briefly, $\mathrm{CAI}_{\text {spec }}$ was assessed as $\mathrm{CAI}_{\text {spec }}=\mathrm{Q}_{\text {spec }} / \mathrm{Q}_{\mathrm{ggG}}$, if $\mathrm{Q}_{\mathrm{Lim}}>\mathrm{Q}_{\mathrm{IgG}}$, or $\mathrm{CAI}=\mathrm{Q}_{\text {spec }} / \mathrm{Q}_{\mathrm{Lim}}$ (IgG), if $\mathrm{Q}_{\mathrm{Lim}}<\mathrm{Q}_{\mathrm{ggG}}$. The variables were calculated as follows: $\mathrm{Q}_{\text {spec }}=$ antigen-specific $\mathrm{IgG}_{\mathrm{CSF}}[\mathrm{AU}] /$ antigen-specific $\mathrm{IgG}_{\text {serum }}$ 
$[\mathrm{AU}] ; \mathrm{Q}_{\mathrm{IgG}}=\mathrm{IgG}_{\mathrm{CSF}} / \mathrm{IgG}_{\text {serum }} ; \mathrm{Q}_{\mathrm{Lim}}(\mathrm{IgG})=0.93 \times\left(\mathrm{Q}_{\mathrm{alb}}{ }^{2}\right.$ $\left.+6 \times 10^{-6}\right)^{0.5}-1.7 \times 10^{-3} ; \mathrm{Q}_{\mathrm{alb}}=\mathrm{alb}_{\mathrm{CSF}} / \mathrm{alb}_{\text {serum }}$ (with alb = albumin). $\mathrm{Q}_{\operatorname{Lim}}(\mathrm{IgG})$ refers to the upper discrimination line of the hyperbolic reference range for the blood-derived IgG in CSF as 0 intrathecal IgG synthesis. Intrathecal antigenspecific antibody synthesis was defined as $\mathrm{CAI}_{\text {spec }} \geq 1.5$. Serum and CSF samples were preincubated with BKV before testing with JCV ELISA and vice versa to assess JCV/BKV cross-reactivity. For the determination of the COV of JCV, $\mathrm{BKV}, \mathrm{KIV}$, and WUV seropositivity, we measured sera from the above-mentioned patients with MS and additional 25 healthy donors (among them seropositive and negative donors) using antigen-specific ELISA. Normalized ODs were calculated by subtracting the mean $\mathrm{OD}$ of negative controls and divided by the OD of 1/500 diluted standard serum. We determined the COV of antigen-specific seropositivity by ranking normalized ODs and calculating the inflection point.

Albumin and total IgG, IgM, and IgA in serum and CSF were quantified by immunonephelometry (Unilabs, Zurich, Switzerland). IgG index was calculated as $\operatorname{IgG}$ index $=\mathrm{Q}_{\mathrm{ggG}} / \mathrm{Q}_{\mathrm{alb}}$ (for $\mathrm{Q}_{\mathrm{IgG}}$ and $\mathrm{Q}_{\mathrm{alb}}$ see above) and IgM index and IgA index each accordingly. IgG index $\geq 0.7$ indicated intrathecal synthesis of IgG. The relative intrathecal fraction of IgM and IgA, respectively $\left(\operatorname{IgM}_{\mathrm{IF}}\right.$ and $\left.\operatorname{Ig} \mathrm{A}_{\mathrm{IF}}\right)$, were calculated according to Reiber. ${ }^{20} \operatorname{IgM}_{\mathrm{IF}} \geq 10 \%$ and $\operatorname{IgA}_{\mathrm{IF}} \geq 10 \%$ indicated significant intrathecal synthesis of IgM and IgA, respectively. OCBs were detected by isoelectric focusing on polyacrylamide gels and immunoblotting using IgG-specific antibodies (Serva, Germany, Heidelberg, Germany). OCBs were considered positive in case of $\geq 2$ additional bands.

\section{Statistical analysis}

Prism v5.0 (GraphPad software, San Diego, CA) was used for statistical analysis. The McNemar test (for dichotomous measures) and Wilcoxon-matched pairs test (for quantitative measures) were used to compare between V0 and V12. To test whether the frequency of loss of intrathecal antibody synthesis specific for a given antigen between V0 and V12 is the same as the frequency of loss of intrathecal antibody synthesis specific for all other antigens between V0 and V12, we used the Fisher exact test. All the 20 antigens tested and recognized by intrathecally produced antibodies were regarded as a priori independent of each other. The primary aim was to compare whether loss of intrathecal JCV-specific antibody synthesis between V0 and V12 was significantly more frequent than the loss of intrathecal antibody synthesis specific for all antigens other than JCV. Probability values of $p<$ 0.05 were considered significant in the primary aim. A second, exploratory aim was to compare the frequency of loss of intrathecal antibody synthesis specific for the following respective antigen between $\mathrm{V} 0$ and $\mathrm{V} 12$ against that for all other respective antigens: (1) JCV against all other antigens, (2) $\mathrm{BKV}$, (3) KIV, (4) WUV, (5) measles, (6) rubella, (7) VZV, (8) mumps, (9) HSV-1, (10) HSV-2, (11) CMV, (12) EBVVCA, (13) EBNA-1, (14) influenza A, (15) influenza B, (16) enterovirus, (17) tetanus, (18) diphtheria, (19) H pylori, (20) $C$ pneumoniae, (21) JCV or BKV, and (22) positive MRZ reaction. In this exploratory aim, probability values of $p<$ $0.00227(0.05 / 22)$ were considered significant according to Bonferroni correction for multiple comparisons.

\section{Data availability}

Anonymized data will be shared upon request by qualified investigators.

\section{Results}

\section{Changes of total immunoglobulin levels in serum and CSF during NAT therapy}

We first analyzed total IgG, IgM, and IgA levels in serum (figure 1, A-C) and CSF (figure 1, D-F) and intrathecal production of total IgG, IgM, and IgA (figure $1 \mathrm{G}-\mathrm{L}$ ) in 15 patients with RRMS (male/female ratio 1:4; mean age 40.13 years [range 18-53 years]) before (V0) and during NAT treatment (V12). Total IgG levels in CSF and intrathecal production of total IgG, as determined by IgG index, decreased significantly during NAT therapy (figure 1D, G, and $\mathrm{J}$ ). In addition, NAT treatment significantly reduced total IgM levels in serum and CSF, intrathecal production of IgM (IgM index), and total IgA levels in CSF (figure 1B, E, F, and H). However, the prevalence of donors showing intrathecal IgG, $\operatorname{IgM}$, or IgA production, i.e., IgG index $\geq 0.7$, or local IgM or IgA production $\geq 10 \%$, did not change significantly during NAT therapy (figure $1 \mathrm{~J}-\mathrm{L}$ ).

\section{Heterogeneity of intrathecal production of pathogen-specific antibodies in untreated patients with MS}

To assess the influence of NAT therapy on antigen-specific IgG responses, we analyzed serum and CSF levels, as well as intrathecal production of antigen-specific antibodies, i.e., antigen-specific $\mathrm{CAI}_{\text {antigen, }}$ at before treatment $(\mathrm{VO} ; \mathrm{n}=$ 15), after 12 months (V12; $\mathrm{n}=15$ ), and after 24 months of NAT treatment (V24; $n=6$ : MS01-MS06) using an array of 20 viral and bacterial antigens (figure 2). The prevalence of donors seropositive for the respective antigens was comparable with data from the literature and did not change during NAT therapy (figure e-1, links.lww.com/NXI/A146). As expected, the spectrum of antigens recognized by intrathecally produced IgG varied considerably among therapy-naive individuals (V0, figures 2 and 3A). Before NAT therapy, intrathecal production of antibodies against $\geq 1$ antigen was detectable in $86.7 \%$ of donors, against $\geq 2$ antigens in $80.0 \%$ of donors (figures 2 and $3 \mathrm{~B}$ ). No intrathecal production of antibodies reactive to any of the 20 antigens tested was observed in 2 donors (13.3\%, MS06 and MS15 at V0 in figure 2), whereas intrathecal production of antibodies against 10 antigens was found in 2 other donors (MS01 and MS07 at V0 in figure 2). The antigens most frequently recognized by intrathecally produced antibodies were measles $(73.3 \%$ of donors), rubella (60.0\%), and VZV (53.3\%), followed by 

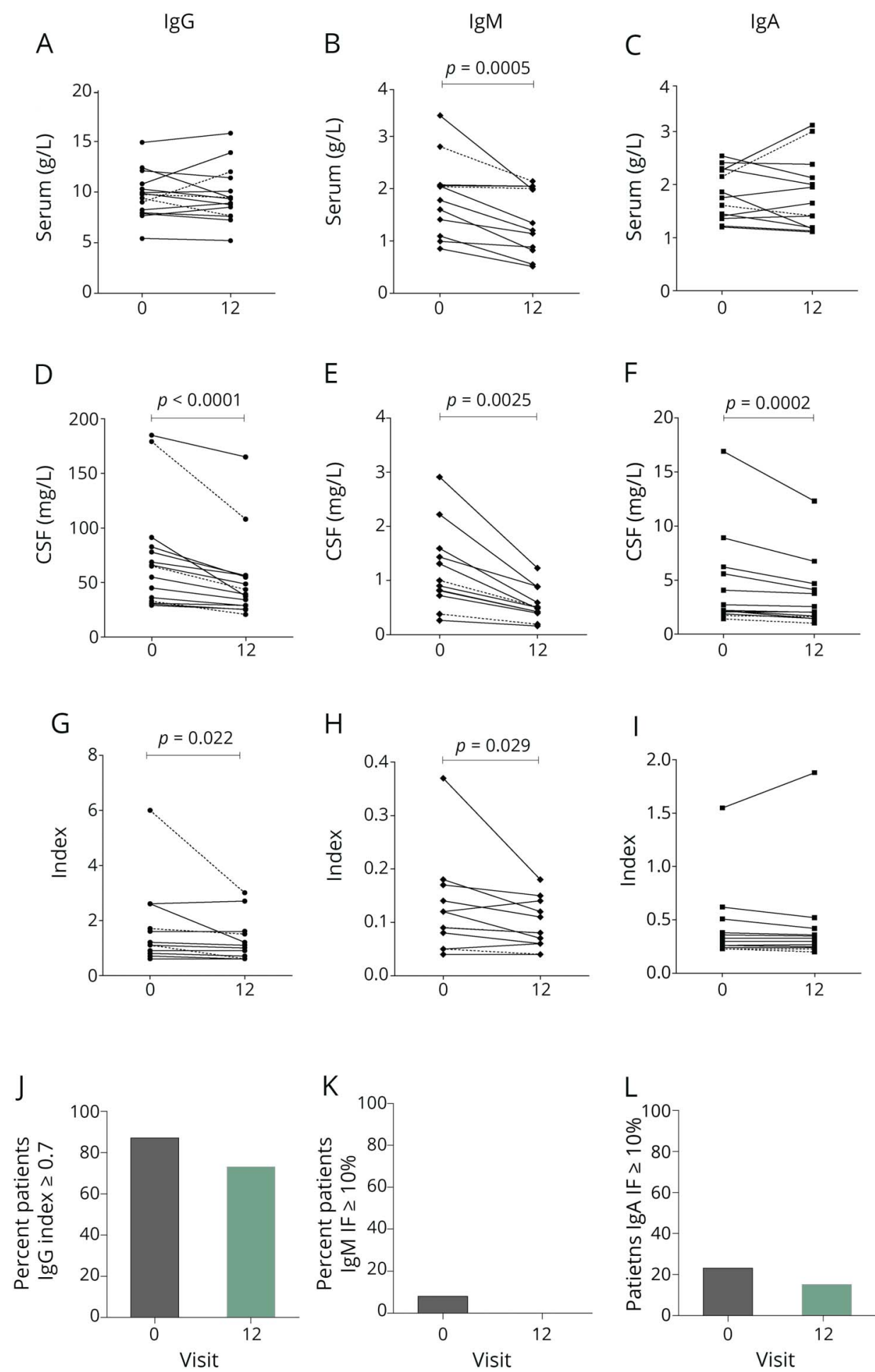

Changes of absolute levels of total lgG, IgM, and IgA in serum (A-C) and CSF (D-F) during NAT therapy are shown. Changes in intrathecal production of total IgG, IgM, and IgA are shown by depicting IgG, IgM, and IgA index (ratio of CSF/serum antibodies normalized to ratio CSF/serum albumin) (G-I), as well as prevalence of patients with significant intrathecal synthesis of IgG, IgM, or IgA (J-L), respectively, as indicated by IgG index $\geq 0.7, \operatorname{lgM}_{\mathrm{IF}} \geq 10 \%$, and $\lg \mathrm{A}_{\mathrm{IF}}$ $\geq 10 \%$, respectively, before (V0) and after 12 months (V12) of NAT treatment $(n=$ $15)$. The $p$ value is shown in case of statistically significant differences. Statistics: Wilcoxon-matched pairs test $(\mathrm{A}-\mathrm{I})$ and MCNemar test (J-L). NAT = natalizumab.

influenza B virus (46.7\%) and C pneumoniae (40.0\%) (figure 3A). MRZ reaction, defined as polyclonal intrathecal antibody reactivity to $\geq 2$ of the 3 antigens measles $(M)$, rubella $(R)$, and zoster (Z), was positive in $73.3 \%$ (figure $3 \mathrm{~B}$ ), consistent with the proportion reported in the literature. ${ }^{10,21}$ Intrathecal synthesis of antibodies against mumps virus (33.3\%), tetanus toxoid (33.3\%), influenza A virus (26.7\%), HSV-1 (20.0\%),
HSV-2 (6.7\%), CMV (6.7\%), and enterovirus (6.7\%) was less frequent. No intrathecal synthesis of antibodies reactive against EBV-VCA, EBNA-1, diphtheria toxoid, or $\mathrm{H}$ pylori was detectable (figures 2 and $3 \mathrm{~A}$ ). Of interest, intrathecal antibody synthesis to the polyomaviruses, KIV (26.7\%), JCV (20.0\%), BKV (20.0\%), and WUV (13.3\%), was detected in some therapy-naive patients. 
Changes of intrathecal production of antigenspecific antibodies during NAT therapy

Only the serum levels of rubella virus-reactive antibodies decreased significantly during NAT therapy, but none of the ones reactive to all other antigens (figure e-2 and e-3, links. lww.com/NXI/A147 and links.lww.com/NXI/A148). In contrast, NAT therapy reduced CSF levels of antibodies reactive to JCV, BKV, KIV, WUV, measles virus, rubella virus, VZV, mumps virus, EBV-VCA, EBNA-1, influenza A virus, influenza $\mathrm{B}$ virus, enterovirus, and tetanus toxoid, but not those reactive to HSV-1, HSV-2, CMV, diphtheria toxoid, $H$ pylori, and $C$ pneumoniae (figure 4 and figure e-2 and e-3, links. lww.com/NXI/A147 and links.lww.com/NXI/A148).
During NAT therapy, the prevalence of donors producing the respective antigen-specific antibodies reduced by $20.0 \%$ in JCV and BKV, respectively, by $13.3 \%$ in KIV and influenza B virus, respectively, by $6.7 \%$ in 6 of 20 antigens, and stayed unchanged or undetectable in 10 of 20 antigens tested (figures 2 and $3 \mathrm{~A}$ ). Three donors showed intrathecal production of antibodies reactive to both JCV and BKV before NAT therapy, and both reactivities were lost in all 3 donors during NAT treatment, although serum JCV- and BKV-specific antibody responses persisted (figure $4, \mathrm{~A}$ and $\mathrm{B}$ ). In addition, these donors showed a persistent positive MRZ reaction. No crossreactivity between JCV- and BKV-specific CSF antibodies was detected at baseline (figure e-4, links.lww.com/NXI/A149).

Figure 2 Antigen spectrum recognized by intrathecally produced antibodies in patients with MS before and during NAT treatment.

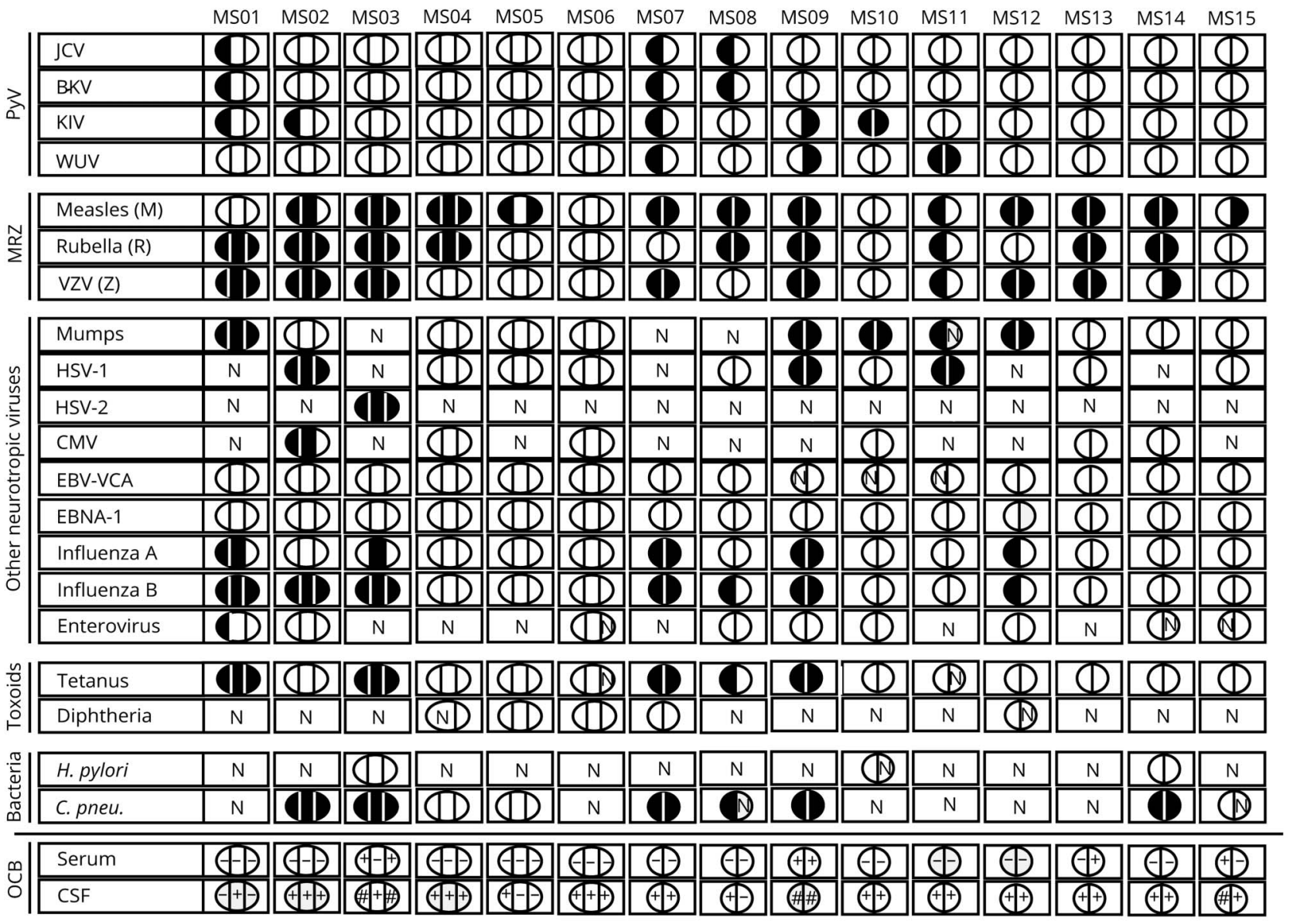

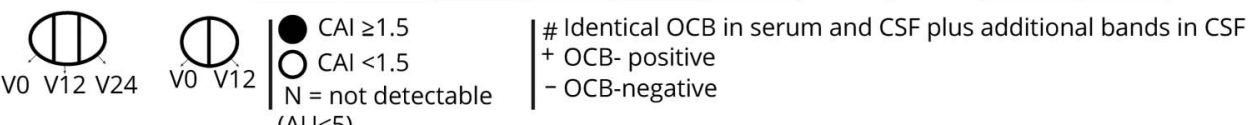

Antigens are divided into polyomaviral VP1 (PyV: JCV, BKV, KIV, and WUV), viral lysates of the MRZ reaction (measles [M], rubella [R], and VZV [Z]), lysates or antigens from other neurotropic viruses (mumps, HSV-1, HSV-2, CMV, EBV-VCA, EBNA-1, influenza A, influenza B, and enterovirus), toxoids (tetanus and diphtheria toxoids), and bacterial antigens (from non-neurotropic $\mathrm{H}$ pylori and from neurotropic $\mathrm{C}$ pneumoniae). Black indicates intrathecal antibody synthesis (CAI $\geq 1.5)$, and white no antigen-specific intrathecal antibody synthesis (CAI < 1.5). Samples with AUs below 5 were considered as not detectable (N). Longitudinal samples of patients with MS were available from before treatment (V0; $n=15)$, after 12 months (V12; $n=15)$, and after 24 months of NAT treatment (V24; $n=6$ : only MS01-MS06). Detection of OCBs in the corresponding serum and CSF samples and/or additional bands in CSF is depicted in the bottom lines. AU = arbitrary unit; CAI = CSF antibody index; EBNA-1 = EBV nuclear antigen-1; EBV = Epstein-Barr virus; EBV-VCA = EBV viral capsid antigen; HSV = herpes simplex virus; JCV = JC polyomavirus; MRZ = measles, rubella, and zoster antigen; $\mathrm{NAT}=$ natalizumab; OCB = oligoclonal band; VZV = varicella zoster virus. 
Figure 3 Prevalence and loss of intrathecal production of antigen-specific antibodies and OCBs before and during NAT treatment

A

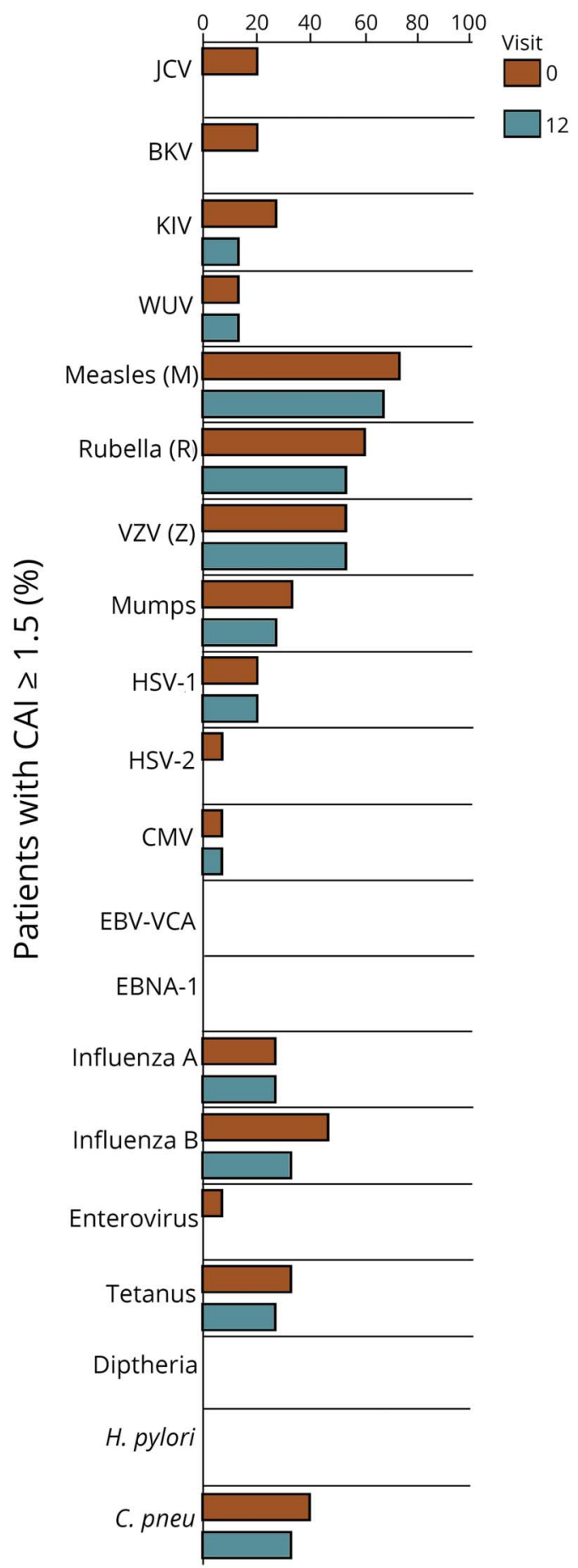

$\mathrm{B}$

Patient with positive MRZ (\%)

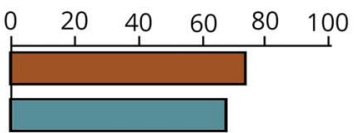

Patients with intrathecal antibodies

against $\geq 2$ Ag's

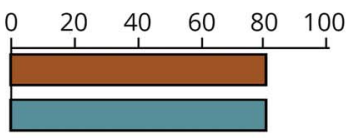

C

Frequency loss CAI $\geq 1.5$

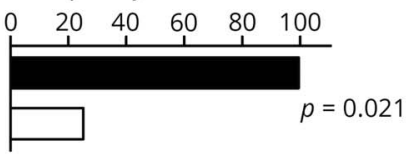

Reactive to JCV

$\square$ Reactive to all other antigens

D

Patients with positive OCB (\%)

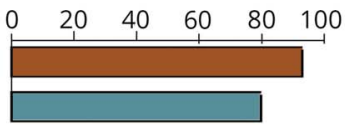

(A) Prevalence of patients showing intrathecal production of antibodies to the antigens indicated, before (V0; $\mathrm{n}=15$, dark gray bars) and after 12 months of NAT treatment (V12; $n=15$, light gray bars). (B) Prevalence of patients with positive MRZ reaction, defined as intrathecal production of antibodies against at least 2 of the 3 MRZ antigens (MRZ virus), before (V0, dark gray bars) and after 12 months of NAT treatment (V12, light gray bars) (upper graph) and prevalence of patients with intrathecal production of antibodies against at least 2 of the 20 antigens analyzed in (A), before (V0, dark gray bars) and after 12 months of NAT treatment (V12, light gray bars) (lower graph). (C) Frequency of loss of intrathecal production of antibodies (CAI $\geq 1.5)$ reactive against JCV (black bar, proportion 3/3) in comparison to the frequency of loss of CAI $\geq 1.5$ specific for all other viral and bacterial antigens tested (white bar, proportion 18/70). (D) Prevalence of patients with positive OCBs as determined by isoelectric focusing before (VO, dark gray bars) and after 12 months of NAT treatment (V12, light gray bars). Statistics: McNemar test (A, B, and D) and Fisher exact test for frequency comparisons (C). In the primary aim, the frequency of loss of CAI $\geq 1.5$ reactive against $J C V$ was compared with that specific for all other antigens, and a probability value of $p<0.05$ was considered significant (C). CAI $=$ CSF antibody index; MRZ = measles, rubella, and zoster antigen; NAT = natalizumab; OCB = oligoclonal band. 

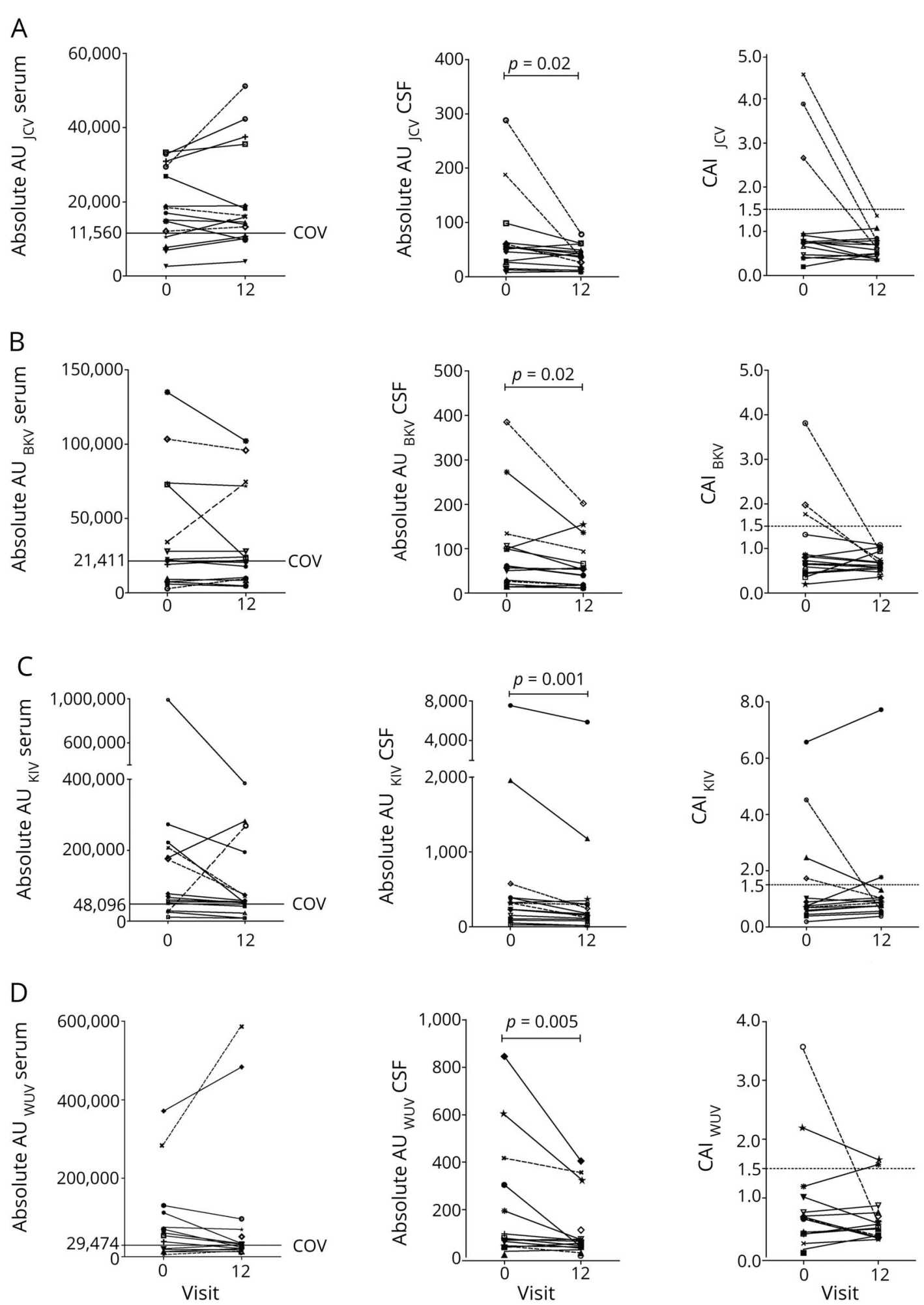

Serum and CSF levels of antibodies reactive to JCV (A), BKV (B), KIV (C), or WUV (D) are depicted in AUs. Intrathecal production of the respective antibodies is

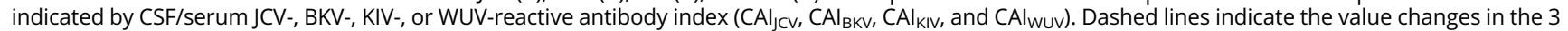
donors with intrathecal production of JCV- and BKV- specific antibodies at V0 and loss thereof at V12 (each $n=15$ ). Continuous horizontal lines indicate COV of seropositivity. Dotted horizontal lines indicate the COV for intrathecal antigen-specific antibody synthesis as defined by CAlspec $\geq 1.5$ ). AU = arbitrary unit; CAI = CSF antibody index; COV = cut-off value; JCV = JC polyomavirus; NAT = natalizumab.

MRZ reaction did not change significantly in all other donors during NAT therapy (figure 3B). Intrathecal production of antibodies against $\geq 2$ antigens persisted in all donors (figure
3B). Intrathecal antibody production against JCV was significantly more frequently lost than the intrathecal production of antibodies reactive against all other antigens except JCV 
(primary aim, $p=0.021$, figure $3 \mathrm{C}$ ). The same was true for the combination of JCV and BKV (exploratory aim, $p=0.00032$ ) after Bonferroni correction for multiple comparisons $(\mathrm{n}=$ 22 ), but not for any of the other antigens (figure e-5, links. lww.com/NXI/A150).

\section{Changes in OCBs during NAT treatment}

OCBs were positive in CSF in $93.3 \%$ of donors before and in $80.0 \%$ of donors during NAT therapy (figures 2 and 3D). Loss of intrathecal OCB production occurred without loss of intrathecal production of antigen-specific antibodies and vice versa (MS13 vs MS02, MS07, MS11, and MS12 in figure 2). OCBs turned positive in 1 patient (MS01) during NAT therapy, which was not accompanied by occurrence of intrathecal production of antigen-specific antibodies (figure 2). Altogether, changes in OCB positivity did not correlate with changes in intrathecal production of antigen-specific antibodies.

\section{Discussion}

Here, we report a detailed analysis of the influence of NAT therapy on the intrathecal production of antiviral and in particular anti-JCV antibodies in patients with MS and possible implications for the development of NAT-PML. Of note, $50 \%-70 \%$ of patients with MS have been reported to be JCV seropositive. $^{22}$ Established risk factors for NAT-PML development are increased levels of anti-JCV antibodies in serum, duration of NAT treatment longer than 2 years, and previous long-term immunosuppressive therapies. ${ }^{22}$ NAT also induces an elevation of B-cell numbers in the peripheral blood, which may serve as a cell pool for JCV infection and dissemination. $^{23,24} \mathrm{NAT}$-induced upregulation of B-cell transcription factors may activate early JCV gene expression, adding to NAT-PML risk. ${ }^{25}$ Occurrence of PML during immunomodulatory treatments and in immunodeficiencies that primarily affect $\mathrm{B}$ cells indicates the importance of antibodies for controlling JCV. ${ }^{4,26}$ Recently, we have discovered viral immune escape mechanisms affecting humoral and adaptive JCV-specific immunity. ${ }^{26,27}$ Patients with MS at onset of NAT-PML showed reduced CSF antibody responses against PML-associated JCV variants, which were closed after immune reconstitution in the CNS for overcoming JCV immune escape. ${ }^{26,28}$ However, it is not yet well understood why patients with MS with higher serum anti-JCV antibody levels are at a higher risk of NAT-PML ${ }^{22}$ and whether the affinity of anti-JCV antibodies and/or their ability to recognize and neutralize multiple JCV variants (including PML-associated strains) is deficient in these individuals. ${ }^{4,26}$ It also remains unclear why NAT therapy is biased to PML and not to any other infectious CNS disease.

By analyzing antibody reactivities against 20 microbial antigens, we demonstrate high interindividual variability in the reactivity of intrathecally produced antibodies against various pathogens in therapy-naive patients with MS. We confirm that intrathecal production of antibodies against $\geq 2$ viral antigens is a frequent feature in therapy-naive patients with MS (found in $80.0 \%$ ), with MRZ reaction being most prevalent (73.3\%). ${ }^{10,13-15,21}$ As an interesting novel observation, we detected intrathecal production of antibodies in therapy-naive patients with MS against tetanus toxoid (33.3\%), JCV (20.0\%), BKV (20.0\%), KIV (26.7\%), and WUV (13.3\%). This response may be part of the MS-associated "polyspecific" CSF antibody response similar to a MRZ-like reaction. ${ }^{10,21}$ What the role of this broad intrathecal humoral immune response in the pathogenesis of MS is and whether it is protective against viral CNS infections are not clear.

In patients with MS, antibody-producing cells (memory B cells, plasmablasts, and plasma cells) frequently circulate between CNS and peripheral blood, ${ }^{29,30}$ indicating a role of peripheral humoral immunity in shaping the CNS-resident B-cell repertoire. The mechanisms establishing the intrathecal B-cell repertoire are as yet unknown. However, MS-associated CNS inflammation might attract antibody-producing cells by chemokine cues. ${ }^{31}$ The probability that B cells producing antibodies against a specific pathogen settle to the CNS might be influenced by the frequency of respective CNS homing antibody-producing cells in peripheral blood and their stochastic migration into the CNS. Additional factors may be expression of molecules that are needed for CNS entry and bystander signals for survival.

Of interest, simultaneous intrathecal JCV- and BKV-specific antibody production was found in $20 \%$ of patients before NAT therapy, but disappeared during NAT therapy in all of these patients with MS, whereas anti-JCV and -BKV serum antibodies and MRZ reaction and CSF OCBs persisted. Initial reports suggested disappearance of OCBs during NAT therapy in $55 \%-67 \%$ of patients, ${ }^{9}$ but our data support the persistence of OCBs during NAT therapy and corroborates more recent reports about less prominent changes in OCB prevalence found in $0 \%-16 \%$ of NAT-treated patients. ${ }^{7,8}$ Methodological differences in OCB detection between the CSF laboratories and differences in MS populations analyzed in the respective studies could account for the discrepant OCB findings seen. Importantly, JCV- and BKV-specific antibody responses were significantly more frequently lost than intrathecal antibody reactivities against other neurotropic viruses and infectious agents, suggesting an antigen-selective loss. BKV shares the highest sequence identity with JCV among human polyomaviruses, and BKV-specific antibodies from healthy donors show frequent cross-reactivity against $\mathrm{JCV}^{26}$ However, BKV causes nephropathy in up to $10 \%$ of kidney transplant recipients and is not considered to be associated with PML, MS, or brain disease.

Differential CNS-migratory properties or requirement of survival factors for JCV- or BKV-specific antibody-producing cells might account for this selective loss. Very Late Antigen (VLA-4) expression allows antibody-producing cells to cross the blood-brain barrier (BBB). ${ }^{32,33}$ Not only VLA-4 
expression levels but also the degree of ligand affinity of VLA4, which may be modulated by the activation state of the cell, determine adhesion and migratory abilities. ${ }^{34,35}$ Lower expression or ligand affinity of VLA-4 could be an important factor to hinder JCV- and BKV-specific antibody-producing cells more efficiently from crossing the BBB during NAT therapy than other pathogen-specific B cells.

On CNS entry, plasmablasts that occupy survival niches successfully differentiate into long-lived plasma cells and become immobile. ${ }^{31}$ In contrast, antibody-producing cells lacking survival cues might eventually undergo apoptosis, and intrathecal antibody secretion might depend on continuous CNS infiltration of peripheral cells. We consider this scenario rather unlikely in the context of JCV- and BKV-specific B cells because the here detected absence of cross-reactivity between JCV- and BKVspecific antibodies in the CNS, which is usually found in sera of healthy donors and patients with $\mathrm{MS}^{26}$ may indicate affinity maturation of CNS homing, initially cross-reactive $\mathrm{B}$ cells to JCVmonospecific and BKV-monospecific cells. Alternatively, intrathecal JCV- and BKV-specific antibody-producing cells might be more dependent on $\mathrm{CD} 4^{+} \mathrm{T}$-cell help for survival and maturation to long-lived plasma cells than B cells specific for other pathogens. Again, NAT may inhibit CNS entry of antiviral $\mathrm{CD} 4^{+}$ $\mathrm{T}$ cells differentially depending on peripheral precursor frequencies, expression levels of VLA-4, and migratory abilities. ${ }^{6,34}$

Whereas $20 \%$ of therapy-naive patients with MS show intrathecal JCV- and BKV-specific antibody production, NAT therapy appears to abrogate these immune reactions preferentially compared with responses against other neurotropic viruses. The observations of this study not only show the previously known interindividual heterogeneity of the intrathecal polyspecific antiviral humoral immune reactions in patients with MS but also indicate intraindividual heterogeneity in the persistence of intrathecal antigen-specific antibody reactivities with some being more stable and persistent (e.g., MRZ reaction) than others (intrathecal JCV-specific antibody synthesis). Assuming that intrathecally produced anti-JCV antibodies are protective, their loss during NAT treatment could result in higher risk for PML development. Limitations of our study are the small cohort size and short observation period, respectively. Larger studies are needed to define how NAT-induced loss of intrathecal JCVspecific antibody production influences PML risk.

\section{Author contributions}

F. Largey and Il. Jelcic had full access to all the data in the study and take responsibility for the integrity of the data and the accuracy of the data analysis. Study concept and design: R. Martin and Il. Jelcic. Acquisition, analysis, or interpretation of data: F. Largey, Iv. Jelcic, M. Sospedra, R. Martin, and Il. Jelcic. Drafting of the manuscript: F. Largey, R. Martin, and Il. Jelcic. Critical revision of the manuscript for important intellectual content: Iv. Jelcic, M. Sospedra, and C. Heesen. Statistical analysis: F. Largey and Il. Jelcic. Administrative, technical, or material support: M. Sospedra, C. Heesen, R. Martin, and Il. Jelcic. Study supervision: Il. Jelcic.

\section{Acknowledgment}

The authors thank all patients who participated in the study; the Section of Neuroimmunology and Multiple Sclerosis Research is supported by the Clinical Research Priority Program (CRPP-MS) of the University of Zurich. The Institute for Neuroimmunology and Clinical Multiple Sclerosis Research was supported by the Gemeinnützige Hertie Stiftung. The authors thank Dr. Robert L. Garcea, Department of Molecular, Cellular, \& Developmental Biology, and The Biofrontiers Institute, University of Colorado at Boulder, CO, for providing BKV-, KIV- and WUV VP1 antigens for this study. They further thank Dr. Patrick Stellmann, Department of Neurology, University Medical Center Hamburg-Eppendorf, Hamburg, Germany, for checking clinical data of the patients, and Katja Steinhagen, Euroimmun, Lübeck, Germany, for technical advice. They are also indebted to Matthias Kirchner, ETH, Zürich, Zürich, Switzerland, for guidance in the statistical analysis of the data.

\section{Study funding}

This study was supported by an unrestricted grant from Biogen Idec, Inc. The Section of Neuroimmunology and Multiple Sclerosis Research is supported by the Clinical Research Priority Program (CRPP-MS) of the University of Zurich. The Institute for Neuroimmunology and Clinical Multiple Sclerosis Research was supported by the Gemeinnützige Hertie Stiftung. Role of the funder/sponsor: the funding source had no role in the design and conduct of the study; collection, management, analysis, and interpretation of the data; preparation, review, or approval of the manuscript; and decision to submit the manuscript for publication.

\section{Disclosure}

F. Largey reports no disclosures. Iv. Jelcic received compensation for serving on a scientific advisory board by Sanofi Genzyme. M. Sospedra has received an unrestricted grant from Biogen Idec. C. Heesen has received speaker honoraries and research grants from Biogen, Genzyme, Merck, Novartis, and Roche. R Martin has served as advisor or member of speaker's boards for Biogen Idec, Novartis, Roche, Genzyme, CellProtect, and Neuway. Furthermore, the group of $\mathrm{R}$ Martin has received unrestricted grants from Biogen Idec and Novartis. Il. Jelcic has received speaker honoraria or unrestricted grants from Biogen Idec and Novartis and has served as advisor for Neuway, Merck, Novartis, and Sanofi Genzyme. Go to Neurology.org/NN for full disclosures.

\section{Publication history}

Received by Neurology: Neuroimmunology \& Neuroinflammation August 15, 2018. Accepted in final form July 31, 2019.

\section{References}

1. Major EO. Progressive multifocal leukoencephalopathy in patients on immunomodulatory therapies. Annu Rev Med 2010;61:35-47.

2. Biogen Tysabri Safety Update. Available at biogen.ch/de_CH/medical-professionals/rxsecure/tysabri.html. Accessed on November 11, 2018.

3. Fine AJ, Sorbello A, Kortepeter C, Scarazzini L. Central nervous system herpes simplex and varicella zoster virus infections in natalizumab-treated patients. Clin Infect Dis 2013;57:849-852. 
4. Jelcic I, Jelcic I, Faigle W, Sospedra M, Martin R. Immunology of progressive multifocal leukoencephalopathy. J Neurovirol 2015;21:614-622.

5. Selter RC, Biberacher V, Grummel V, et al. Natalizumab treatment decreases serum IgM and IgG levels in multiple sclerosis patients. Mult Scler 2013;19:1454-1461.

6. Stüve O, Marra CM, Jerome KR, et al. Immune surveillance in multiple sclerosis patients treated with natalizumab. Ann Neurol 2006;59:743-747.

7. Warnke C, Stettner M, Lehmensiek V, et al. Natalizumab exerts a suppressive effect on surrogates of B cell function in blood and CSF. Mult Scler 2015;21:1036-1044.

8. Harrer A, Tumani H, Niendorf S, et al. Cerebrospinal fluid parameters of B cell-related activity in patients with active disease during natalizumab therapy. Mult Scler 2013; 19:1209-1212.

9. Mancuso R, Franciotta D, Rovaris M, et al. Effects of natalizumab on oligoclonal bands in the cerebrospinal fluid of multiple sclerosis patients: a longitudinal study. Mult Scler 2014;20:1900-1903.

10. Stangel M, Fredrikson S, Meinl E, Petzold A, Stüve O, Tumani H. The utility of cerebrospinal fluid analysis in patients with multiple sclerosis. Nat Rev Neurol 2013;9: 267-276.

11. Bonnan M. Intrathecal IgG synthesis: a resistant and valuable target for future multiple sclerosis treatments. Mult Scler Int 2015;2015:296184.

12. Weber T, Trebst C, Frye S, et al. Analysis of the systemic and intrathecal humoral immune response in progressive multifocal leukoencephalopathy. J Infect Dis 1997; $176: 250-254$.

13. Salmi A, Reunanen M, Ilonen J, Panelius M. Intrathecal antibody synthesis to virus antigens in multiple sclerosis. Clin Exp Immunol 1983;52:241-249.

14. Felgenhauer K, Schadlich HJ, Nekic M, Ackermann R. Cerebrospinal fluid virus antibodies. A diagnostic indicator for multiple sclerosis? J Neurol Sci 1985;71: 291-299.

15. Derfuss $\mathrm{T}$, Gürkov R, Then Bergh F, et al. Intrathecal antibody production against chlamydia pneumoniae in multiple sclerosis is part of a polyspecific immune response. Brain 2001;124:1325-1335.

16. Warnke C, von Geldern G, Markwerth $P$, et al. Cerebrospinal fluid JC virus antibody index for diagnosis of natalizumab-associated progressive multifocal leukoencephalopathy. Ann Neurol 2014;76:792-801.

17. Polman CH, Reingold SC, Edan G, et al. Diagnostic criteria for multiple sclerosis: 2005 revisions to the "McDonald criteria". Ann Neurol 2005;58:840-846.

18. Kean JM, Rao S, Wang M, Garcea RL. Seroepidemiology of human polyomaviruses. PLoS Pathog 2009;5:e1000363.

19. Aly L, Yousef S, Schippling S, et al. Central role of JC virus-specific CD4+lymphocytes in progressive multi-focal leucoencephalopathy-immune reconstitution inflammatory syndrome. Brain 2011;134:2687-2702.
20. Reiber H. Cerebrospinal fluid-physiology, analysis and interpretation of protein patterns for diagnosis of neurological diseases. Mult Scler 1998;4:99-107.

21. Reiber H, Ungefehr S, Jacobi C. The intrathecal, polyspecific and oligoclonal immune response in multiple sclerosis. Mult Scler 1998;4:111-117.

22. Plavina T, Subramanyam M, Bloomgren G, et al. Anti-JC virus antibody levels in serum or plasma further define risk of natalizumab-associated progressive multifocal leukoencephalopathy. Ann Neurol 2014;76:802-812.

23. Frohman EM, Monaco MC, Remington G, et al. JC virus in CD34+ and CD19+ cells in patients with multiple sclerosis treated with natalizumab. JAMA Neurol 2014;71: 596-602.

24. Planas R, Jelčić I, Schippling S, Martin R, Sospedra M. Natalizumab treatment perturbs memory- and marginal zone-like B-cell homing in secondary lymphoid organs in multiple sclerosis. Eur J Immunol 2012;42:790-798.

25. Meira M, Sievers C, Hoffmann F, et al. Natalizumab-induced POU2AF1/Spi-B upregulation: a possible route for PML development. Neurol Neuroimmunol Neuroinflamm 2016;3:e223. doi:10.1212/NXI.0000000000000223.

26. Jelcic I, Combaluzier B, Jelcic I, et al. Broadly neutralizing human monoclonal JC polyomavirus VP1-specific antibodies as candidate therapeutics for progressive multifocal leukoencephalopathy. Sci Transl Med 2015;7:306ra150.

27. Jelcic I, Jelcic I, Kempf C, et al. Mechanisms of immune escape in central nervous system infection with neurotropic JC virus variant. Ann Neurol 2016;79:404-418.

28. Ray U, Cinque P, Gerevini S, et al. JC polyomavirus mutants escape antibodymediated neutralization. Sci Transl Med 2015;7:306ra151.

29. Palanichamy A, Apeltsin L, Kuo TC, et al. Immunoglobulin class-switched B cells form an active immune axis between CNS and periphery in multiple sclerosis. Sci Transl Med 2014;6:248ra 106.

30. Stern JN, Yaari G, Vander Heiden JA, et al. B cells populating the multiple sclerosis brain mature in the draining cervical lymph nodes. Sci Transl Med 2014;6:248ra107.

31. Radbruch A, Muehlinghaus G, Luger EO, et al. Competence and competition: the challenge of becoming a long-lived plasma cell. Nat Rev Immunol 2006;6:741-750.

32. Lehmann-Horn K, Sagan SA, Bernard CC, Sobel RA, Zamvil SS. B-cell very late antigen-4 deficiency reduces leukocyte recruitment and susceptibility to central nervous system autoimmunity. Ann Neurol 2015;77:902-908.

33. Alter A, Duddy M, Hebert $S$, et al. Determinants of human B cell migration across brain endothelial cells. J Immunol 2003;170:4497-4505.

34. Niino M, Bodner C, Simard ML, et al. Natalizumab effects on immune cell responses in multiple sclerosis. Ann Neurol 2006;59:748-754.

35. Hyduk SJ, Oh J, Xiao H, Chen M, Cybulsky MI. Paxillin selectively associates with constitutive and chemoattractant-induced high-affinity alpha4betal integrins: implications for integrin signaling. Blood 2004;104:2818-2824. 


\section{Neurology \\ Neuroimmunology \& Neuroinflammation}

Effects of natalizumab therapy on intrathecal antiviral antibody responses in MS

Fabienne Largey, Ivan Jelcic, Mireia Sospedra, et al.

Neurol Neuroimmunol Neuroinflamm 2019;6;

DOI 10.1212/NXI.0000000000000621

This information is current as of September 25, 2019

\section{Updated Information \& Services}

References

Citations

Subspecialty Collections

Permissions \& Licensing

Reprints including high resolution figures, can be found at:

http://nn.neurology.org/content/6/6/e621.full.html

This article cites 34 articles, 6 of which you can access for free at: http://nn.neurology.org/content/6/6/e621.full.html\#\#ref-list-1

This article has been cited by 3 HighWire-hosted articles: http://nn.neurology.org/content/6/6/e621.full.html\#\#otherarticles

This article, along with others on similar topics, appears in the following collection(s):

Cerebrospinal Fluid

http://nn.neurology.org//cgi/collection/cerebrospinal_fluid Multiple sclerosis

http://nn.neurology.org//cgi/collection/multiple_sclerosis

Information about reproducing this article in parts (figures,tables) or in its entirety can be found online at:

http://nn.neurology.org/misc/about.xhtml\#permissions

Information about ordering reprints can be found online:

http://nn.neurology.org/misc/addir.xhtml\#reprintsus

Neurol Neuroimmunol Neuroinflamm is an official journal of the American Academy of Neurology.

Published since April 2014, it is an open-access, online-only, continuous publication journal. Copyright

Copyright $\odot 2019$ The Author(s). Published by Wolters Kluwer Health, Inc. on behalf of the American

Academy of Neurology.. All rights reserved. Online ISSN: 2332-7812.

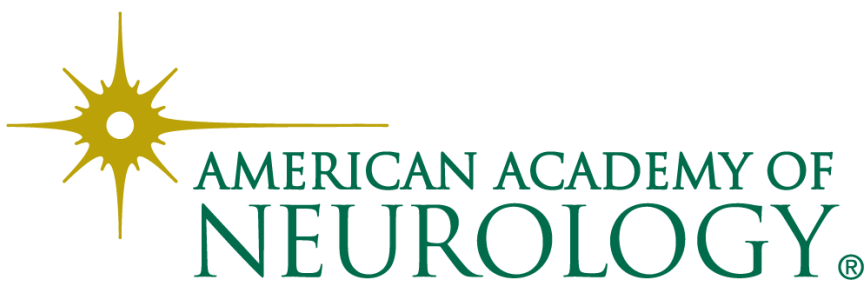

